\title{
Sakubitril/valsartan fiyat-etkinlik avantajı sunuyor mu?
}

\author{
Dr. Hakan Altay
}

Başkent Üniversitesi Tıp Fakültesi, İstanbul Hastanesi, Kardiyoloji Anabilim Dalı, İstanbul

Kalp yetersizliği (KY) dünya genelinde hem mortalite hem de morbiditenin başlıca nedeni olarak evrensel bir halk sağlığı sorunu olmaya devam etmektedir. ${ }^{[1]}$ Özellikle yaşlanan popülasyona bağlı dünyada 63 milyon insan KY'den etkilenmiş bulunuyor. ${ }^{[2]}$ Amerika'da hastane yatışlarının en önde gelen nedeni KY'dir ve yılda 1 milyondan fazla hasta KY nedeni ile hastaneye yatmaktadir. ${ }^{[3]}$ Amerika'da KY nedenli tahmini sağlık harcaması 2012 yılında 31 milyar dolar iken 2030 yılında bu rakamın 70 milyar dolara çıkacağı düşünülüyor ve tüm sağlık harcamalarının \%2-3'ünü oluşturmaktadır. ${ }^{[4]}$ Son 30 yılda KY farmakolojik tedavisi diüretik ve digoksin temelli tedaviden 'hastalığın seyrini değiştiren' (ACEi/ARB, $\mathrm{BB}, \mathrm{MRA}$ ) tedavilere doğru değişmiştir. Bu ilaçlar ile mortalitede önemli azalma sağlanırken, hastane yatışları halen yüksek seyretmeye devam etmiştir. Kararlı KY hastaları için yıllık hastane yatış gereksinimi \%6-7 iken, akut KY ile yatan hastalarda bu oran \%25'lerin üzerine çıkmaktadır. ${ }^{[5]} \mathrm{KY}$ için kullanılan sağlık harcamalarının büyük bir bölümünü hastane yatışları oluşturmaktadır. ${ }^{[6]}$ Daha da ötesi eldeki en iyi tedavilerin optimal dozlarda kullanımı bile KY hastalarının son evreye (EVRE D) ilerlemelerini engelleyememiştir. Bu evrede hastane yatışları daha da artmaktadır. $\mathrm{Bu}$ evrede kullanılan transplantasyon, sol ventrikül destek cihazları (LVAD) ve palyatif tedavi maliyetini katlamaktadır. Bu gerçeklere rağmen son 10 yılda KY farmakolojik tedavisinde sadece birkaç yeni ilaç onaylanırken, çoğu hastalığ KY ile eşdeğer mortalite ve morbiditeye sahip onkolojide sadece 2008 yılında 63 ilaç onaylanmıştır. ${ }^{[7]} 2014$ yılında sonuçlanan PARADIGM HF çalışmasında hem kardiyovasküler ve tüm nedenlere bağlı mortalitede, hem hastane yatışlarında ve hem de hayat kalitesinde enaprile karşı gösterdiği muazzam üstünlük nedeni ile sakubitril/valsartan 2015 yılında hem Amerika İlaç ve Gıda Dairesi (FDA) hem de Avrupa İlaç Ajansı (EMA) tarafından onaylanmıştır. Akabinde de 2016'da Avrupa, 2017'de Amerika KY kılavuzlarında sınıf 1 öneri düzeyi ile
New York Kalp Cemiyeti evre II ve III hastalarda kullanılması tavsiye edilmeye başlamıştır.

Mortalite, hastane yatışlarında ve hayat kalitesinde çok net yararı gösterilen bu ilacın, yakın zamanda gerçekleştirilen çok merkezli kayıt çalışması gösteriyor ki, klinik pratikte kullanım endikasyonu olan sadece \%13 hasta sakubitril/valsartan kullanmaktadır. ${ }^{[8]}$ Bunun önemli nedenlerinden biri klinik kayıtsızlık iken, diğer önemli nedeni de maliyet endişesidir. Peki gerçekten sakubitril/valsartan maliyet etkin mi? Öncelikle, sakubitril/valsartan hastane yatışlarındaki azalma ile birlikle hayat kalitesinde gösterdiği iyileşme ile maliyet etkin olmaya adaydır. Bunun yanında yakın zamanda sonuçlanan PROVE-HF çalışmasında, sakubitril/valsartan ile 1 yıllık kullanım sonunda ejeksiyon fraksiyonunda (EF) ortalama \%9.5'luk bir artış gözlenmiş ve \%25 hastada EF'deki artış \%13 ve üzerinde gerçekleşmiştir. ${ }^{[9]}$ EF' deki bu artış şu ana kadar KY'de kullanılan hiçbir ilaç ile gösterilemedi. Özellikle EF'de yaratacağı bu artış bu ilacın, KY'de kompleks ve pahalı girişimler olan intrakardiyak defibrillatör (IKD) ve kardiyak resenkronizasyon tedavi (KRT) ihtiyacını azaltma potansiyeli ile de maliyeti azaltabileceği izlenimi vermektedir. Sakubitril/valsartanın KY tersine yeniden şekillenmeye katkısı nedeni ile de ileri evre tedavi modalitelerinin (transplantasyon, LVAD) ihtiyacını azaltarak KY'nin sağlık sistemi üzerindeki yükünü azaltma potansiyeli de mevcutdur.

Amerika'da Markov model kullanılarak yapılan bir maliyet-etkinlik analizinde, ortalama 63 yaşındaki hastalarda enalaprile göre sakubitril/valsartan kullanımının kaliteye göre ayarlanmış yaşam yılı başına (QALY) artan maliyet etkinlik oran1 (ICER) 45.017 dolar olarak hesapland..$^{[10]} \mathrm{Bu}$ rakam hem yeni bir tedavi veya girişimin maliyet-etkin olması için kabul edilen 50.000 dolar eşiğinin altında kalmakla birlikte, ilk kez onaylanan ve önemli mortalite ve morbidite yararı gösteren diğer KY tedavi girişimlerini maliyetinin de altındadır. Örneğin IKD ve CRT için ICER de- 
ğerleri 35.000-108.000 dolar arasında iken, ${ }^{[11]}$ LVAD için ICER kazanılan kaliteye göre ayarlanmış yaşam y1lı başına $120.000-300.000$ arasındadır. ${ }^{[12]} 5$ y1llık ortalama sağ kalımı olan bir hastalık da mortalitede $\% 20$ azalmayı vaat eden bir ilaç için geniş bir fiyat aralığında bu rakamlar maliyet-etkin olabilir. Yine PARADIGM HF çalışmasında standart tedaviyi optimal düzeyde alan hastalarda her iki yılda bir hastaneye yatış gerekmiştir. Hastaneye yatışların hayat kalitesinde yaratacağı tahribatı da göz önüne aldığınızda, hastane yatışlarında \%20'lik ve 30 gün içinde tekrar yatışlarda \%36'lık bir azalmanın hayat kalitesine katacağı iyileşmede geniş bir fiyat aralığında bu ilacın maliyet etkinliğini göstermektedir. Ve en önemlisi de her hastane yatışın 10.000-27.000 dolar maliyet yaratacağı da göz önüne alındığında sakubitril/valsartanın bu ICER oranları ile net bir maliyet-etkinlik avantajı sunacağı aşikardır. Bütün bu faktörler düşünüldüğünde sakubitril/valsartanın kazanılan kaliteye göre ayarlanmış yaşam yılı başına ICER değerleri 150.000 dolar altındaki her rakamda bile maliyet-etkin olacağını gösteriyor. Daha da ötesi ACC/AHA kaliteye göre ayarlanmış yaşam yılı başına ICER 150.000 değerini orta bir değer olarak belirlemiştir. ${ }^{[13]}$ Ayrıca şunu da belirtmek gerekir ki, bütün bu hesaplamalar sakubitril/valsartanın 2023'de patent süresinin bitip fiyatının düşeceği hesaba katılmadan yapılmıştır. Amerika'dan başka bir maliyet-etkinlik analizinde, enaprile karşın kaliteye göre ayarlanmış yaşam yılı başına (QALY) yaşam boyu (40 y1l) kullanmak ile kazanılan kaliteye göre ayarlanmış yaşam yılı başına ICER oranının 50.959 dolar olduğu görülüyor. ${ }^{[14]}$ Üçüncü yılda bu oran 250.000 dolar iken, 9. y1lda 100.000 dolara ve tüm yaşam ömrü düşünüldüğünde ancak 50.000 dolara yaklaşıldığı görülüyor. $\mathrm{Bu}$ analizde, tedavi süresinin maliyet-etkinlikdeki esas belirleyici olduğunu göstermesi açısından önemlidir. Sakubitril/valsartanın Amerikada tıbbi bakım sigortasına maliyeti yıllık 4560 dolardır. Bu rakam birçok jeneriği olan ACEI'lere göre epeyi fazla bir rakamdır. Bu yüzden bu ilacı özellikle hafif KY'de erken yaşta zaman kaybetmeden başlamak yaratacağı maliyet-etkinlik avantaj1 açısından muazzam önem taşımaktadır.

Singapur'da yapılan bir maliyet etkinlik analizinde sakubitril/valsartanın enalaprile göre kazanılan kaliteye göre ayarlanmış yaşam yılı başına ICER oranı 55.198 dolar bulundu.$^{[15]} \mathrm{Bu}$ ICER oranı Amerika verilerine benziyor. Fakat rakamların tek başına bir anlamı olmadığını göstermesi açısından Singapur'daki bu analiz de bize karşılaştırma yapabilmek için önemli veri sunuyor. Singapur'da kardiyovasküler yararları gösterilen standart ilaçların ICER oranı 8000 dolar hesaplanmaktadır. Yine karşılaştırma yapılabilmesi için belirtmekte fayda var. Amerika'da hastaneye yatış ve tekrar yatış maliyeti 10.000 ve 11.363 dolar iken, bu rakamlar Singapur'da 3357 ve 4317 dolardır. Buna göre mevcut fiyatlarda sakubitril/valsartan Sinagpur'da maliyet etkin olarak görünmemektedir. $\mathrm{Bu}$ analize göre sakubitril/valsartanın Singapur'da maliyet-etkin sayılabilmesi için fiyatlarında \%32-70 arasında indirim yapılması gerekmektedir.

Almanya'da sakubitril/valsartan ile yapılan maliyet etkinlik analizinde, enalaprile göre sakubitril/ valsartan kullanılmasının kazanılan kaliteye göre ayarlanmış yaşam yılı başına ICER oranı 23.400 euro hesapland1. ${ }^{[16]} \mathrm{Bu}$ rakam Almanya' da KY tedavisi için onaylanmış diğer tedaviler ile eşdeğer veya daha aşağıda bir rakama denk geliyor. Daha da ötesi maliyet-etkin olması bir ilacın Almanya'da geri ödenebilmesi için şart değildir. Sakubitril/valsartan'ın Almanyada marketde yaygın kullanımı sağlık harcamalarında yaratacağı artış <\%0.04 olarak hesaplanmıştır. Almanya'da sakubitril/valsartanın aylık maliyeti 160 euro'dur.

Türkiye'de sakubitril/valsartan Kasım 2016'da ruhsat onayı almıştır fakat dört yıldır klinik kullanımda olmasına rağmen geri ödeme alamamıştır. Türkiye'de sakubitril/valsartan ile ilgili maliyet-etkinlik analizi henüz yapılmamıştır. 2016' da gerçekleştirilen Delphi paneli sonuçlarına göre Türkiye'de düşük ejeksiyon fraksiyonlu KY (DEFKY) hastalarının \%43'ü hastaneye yatmakta, bunların \%16.9'u yoğun bakımlarda olmakta ve ortalama yatış süreleri de 6.7 gün olmaktadır. Hastaların \%32'si yılda ortalama 1.64 kez hastaneye yatmaktadır. ${ }^{[17]}$ Günlük yatış maliyeti 353 TL'dir. Kişi başına IKD maliyeti 12.674 TL, KRT 16.053 TL ve LVAD 202.705 TL'dir. Türkiye'de ACEi günlük maliyeti 0.23 TL'dir. Sakubitril/valsartan'ın günlük maliyeti Amerika ve Avrupa'dan çok daha düşük olmakla birlikte Türkiye'de 16.7 TL'dir. Hastane yatışlarında, IKD, KRT ve LVAD ihtiyacında yaratacağ1 azalma ile birlikte hayat kalitesinde iyileşme ve kaybolan işgücünü tekrar yerine koymayı hesaba kattığınızda sakubitril/valsartan'ın özellikle hafif-orta semptomları olan DEFKY hastalarında Türkiye'de de maliyet etkin olacağından şüphe yoktur.

Özetle KY tüm dünyada giderek büyüyen sayıları, mortalite ve hastane yatışlara etkisi ve sağlık sistemine hem iş yükü hem de maliyet yükü ile bir sorun olmaya devam etmektedir. Hasta sayıları ve kullanılan ilaç ve cihaz tedavilerinin çokluğu düşünüldüğünde ma- 
liyet-etkinlik analizleri çok önemlidir. Bu analizlere göre ilaç fiyatları ülkelere göre ayarlanmalıdır. Fakat, mottosu tüm hastalara eşit tedavi hakkı olan KY'de, yararları birçok bakımdan tartışmasız olan sakubitril/ valsartan'ın tüm hastaların kullanımına sunulabilmesi için devlet geri ödeme kurumları ile ilaç endüstrisinin orta yolda buluşması mutlak bir mecburiyettir.

\section{Kaynaklar}

1. Mosterd A, Hoes AW. Clinical epidemiology of heart failure. Heart 2007;93 1137-46.

2. GBD 2016 Disease and Injury Incidence and Prevalence Collaborators. Global, regional, and national incidence, prevalence, and years lived with disability for 328 diseases and injuries for 195 countries, 1990-2016: a systematic analysis for the Global Burden of Disease Study 2016. Lancet 2017;390:1211-59.

3. Mozaffarian D, Benjamin EJ, Go AS, Arnett DK, Blaha MJ, Cushman $\mathrm{M}$, et al. Heart disease and stroke statistics--2015 update: a report from the American Heart Association. Circulation 2015;131:e29 322.

4. Heidenreich PA, Albert NM, Allen LA, Bluemke DA, Butler J, Fonarow GC, et al. Forecasting the impact of heart failure in the United States: a policy statement from the American Heart Association. Circ Heart Fail 2013;6:606-19.

5. Crespo-Leiro MG, Anker SD, Maggioni AP, Coats AJ, Filippatos G, Ruschitzka F, et al. European Society of Cardiology Heart Failure Long-Term Registry (ESC-HF-LT): 1-year follow-up outcomes and differences across regions. Eur J Heart Fail 2016;18:613-25.

6. Healthcare Cost and Utilization Project (HCUP). HCUP facts and figures. Statistics on hospital-based care in the United States, 2008. Available at: https://www.hcup-us.ahrq.gov/reports/factsandfigures/2008/TOC_2008.jsp. Accessed Jul 14, 2020.

7. Hematology/Oncology (Cancer) Approvals and Safety notifications. Available at: https://www.fda.gov/drugs/resources-informationapproved-drugs/hematologyoncology-cancer-approvals-safety-notifications. Accessed Jul 14, 2020.
8. Greene SJ, Butler J, Albert NM, DeVore AD, Sharma PP, Duffy CI, et al. Medical Therapy for Heart Failure With Reduced Ejection Fraction: The CHAMP-HF Registry. J Am Coll Cardiol 2018;72:351-66.

9. Januzzi JL Jr, Prescott MF, Butler J, Felker GM, Maisel AS, McCague $\mathrm{K}$, et al. Association of Change in N-Terminal Pro-B-Type Natriuretic Peptide Following Initiation of Sacubitril-Valsartan Treatment With Cardiac Structure and Function in Patients With Heart Failure With Reduced Ejection Fraction. JAMA 2019;322:1-11.

10. Gaziano TA, Fonarow GC, Claggett B, Chan WW, DeschaseauxVoinet C, Turner SJ, et al. Cost-effectiveness Analysis of Sacubitril/ Valsartan vs Enalapril in Patients With Heart Failure and Reduced Ejection Fraction. JAMA Cardiol 2016;1:666-72.

11. Sanders GD, Hlatky MA, Owens DK. Cost-effectiveness of implantable cardioverter-defibrillators. N Engl J Med 2005;353:1471-80.

12. Rohde LE, Bertoldi EG, Goldraich L, Polanczyk CA. Costeffectiveness of heart failure therapies. Nat Rev Cardiol 2013;10:33854.

13. Anderson JL, Heidenreich PA, Barnett PG, Creager MA, Fonarow GC, Gibbons RJ, et al. ACC/AHA statement on cost/value methodology in clinical practice guidelines and performance measures: a report of the American College of Cardiology/American Heart Association Task Force on Performance Measures and Task Force on Practice Guidelines. Circulation 2014;129:2329-45.

14. King JB, Shah RU, Bress AP, Nelson RE, Bellows BK. CostEffectiveness of Sacubitril-Valsartan Combination Therapy Compared With Enalapril for the Treatment of Heart Failure With Reduced Ejection Fraction. JACC Heart Fail 2016;4:392-402.

15. Liang L, Bin-Chia Wu D, Aziz MIA, Wong R, Sim D, Leong KTG, et al. Cost-effectiveness of sacubitril/valsartan versus enalapril in patients with heart failure and reduced ejection fraction. J Med Econ 2018;21:174-81.

16. Gandjour A, Ostwald DA. Sacubitril/Valsartan (LCZ696): A Novel Treatment for Heart Failure and its Estimated Cost Effectiveness, Budget Impact, and Disease Burden Reduction in Germany. Pharmacoeconomics 2018;36:1285-96.

17. Aras D, Aydoğdu S, Bozkurt E, Çavuşoğlu Y, Eren M, Erol Ç, et al. Cost of heart failure management in Turkey: results of a Delphi Panel. Anatol J Cardiol 2016;16:554-62. 